\title{
Ischemic mitral regurgitation: Back to the drawing boards
}

\author{
Paul Kurlansky, MD
}

See related article on pages 752-61.

Ischemic functional mitral regurgitation remains a common and morbid clinical entity, for which no simple therapeutic approach seems satisfactory. Diagnostic criteria usually include mitral regurgitation (MR) after myocardial infarction (MI) with 1 or more segmental wall motion abnormalities, significant coronary artery disease in 1 of the territories supplying the wall motion abnormalities, and structurally normal mitral valve leaflet and chordae tendinae.

Reported incidence may vary widely depending on the diagnostic techniques used, the time of the diagnosis after the MI, the treatment paradigm of the MI, and the heterogeneity of MR patients included in the study. However, moderate-to-severe ischemic MR essentially doubles the mortality of post-MI patients. ${ }^{2,3}$ Unfortunately, the plethora of medical and surgical approaches to this problem attests to the lack of success of any single modality in improving mortality. ${ }^{4}$

Pathophysiology relates to ventricular remodeling after myocardial injury with ventricular and annular enlargement, apical and lateral papillary muscle migration, leaflet tethering, and alteration of closing forces. These processes interfere with appropriate leaflet coaptation and thus result in variable degrees of MR that can fluctuate dynamically as a function of volume status, afterload, heart rhythm, and residual ischemia. In essence, the valvular dysfunction is a manifestation of a ventricular problem. This paradigm may help to explain the paradoxical observation that even though MR significantly impairs the prognosis of patients with ischemic cardiomyopathy, surgical correction of regurgitation does not seem to improve long-term survival., Although provocative, these observational studies, even though they use propensity-score matching, do not control well for the stage of the disease, the medical therapy followed, or the specific type of repair employed. They therefore yield useful but not definitive information. They do, however, cause us to more carefully assess the underlying pathophysiology.

\footnotetext{
From the Department of Surgery, Columbia University, New York, NY.

Disclosures: Author has nothing to disclose with regard to commercial support.

Received for publication Nov 10, 2014; accepted for publication Nov 13, 2014; available ahead of print Dec 6, 2014.

Address for reprints: Paul Kurlansky, MD, Department of Surgery, Columbia University, Black Building 210,650 W 168th St, New York, NY 10032 (E-mail: pk2245@ cumc.columbia.edu).

J Thorac Cardiovasc Surg 2015;149:665-6

$0022-5223 / \$ 36.00$

Copyright (c) 2015 by The American Association for Thoracic Surgery

http://dx.doi.org/10.1016/j.jtcvs.2014.11.023
}

First, even though it is ventricular dysfunction that underlies MR, mitral incompetence itself leads to volume overload, further aggravating ventricular sphericity and annular dilatation. Moreover, chronic MR increases ventricular wall stress, owing to diastolic loading. ${ }^{7}$ Initial compensation involves eccentric ventricular hypertrophy where synthesis of sarcomeres preserves ventricular compliance and preload recruitable reserve. Uncorrected, this leads to a shift in the gene expression of the myocytes and extracellular matrix, from hypertrophy to fibrosis and apoptosis, with myocyte "drop-out" and increased interstitial fibrosis. 8,9

Surgical success may well rely as much on timing as technique. Future evaluation may require more sophisticated evaluation of the degree of ventricular thinning and fibrosis, rather than mere assessment of the ventricular dimensions and mitral incompetence. Unfortunately though, clinical reality is ever more complex than experimental constructs, and the ability to distinguish the remodeling that is due to MR from that due to the underlying ischemic myopathy may be limited, even with advanced imaging techniques.

In an effort to better elucidate the role of surgery for this disease complex, the Cardiothoracic Surgical Trials Network recently conducted its prospective randomized control trial (PRCT) study comparing mitral valve repair versus replacement for severe ischemic MR. ${ }^{10}$ Owing to the exigencies of recruiting adequate numbers of patients, a primary endpoint of left ventricular end systolic volume index was chosen. Based on literature review, a reduction of $20 \%$ in valve repair was anticipated. Mysteriously, the reporting of study parameters failed to disclose the evidence base for the estimation of a $30 \%$ reduction in the index from valve replacement. ${ }^{11}$ Therefore, the observed $10 \%$ average reduction in both study arms left the investigators woefully short of sufficient data to provide robust analysis of study outcomes.

Despite these shortcomings, Kron and colleagues, ${ }^{12}$ in this issue of the Journal, attempt to decipher the clinical characteristics that might help identify those patients most likely to experience return of MR after repair. The rate of recurrence, $23.8 \%$ moderate and $9.9 \%$ severe at 30 days, and $38.0 \%$ moderate and $10.1 \%$ at 24 months is fairly consistent with that previously reported, ${ }^{13-15}$ although the apparent absence of progression from moderate to severe is notable (but difficult to decipher with death as a competing variable). With considerable clinical acumen and statistical erudition, the authors were able to generate a model predictive of the combined endpoint of MR recurrence and death with an admirable C-statistic of 0.82 . 
However, the elements act somewhat as a unified entitythe numbers did not permit a model sufficiently robust to evaluate the relative contribution of each element. Therefore, the clinician confronted with a patient who has both similarities and dissimilarities to the patient described by the model will be somewhat at a loss to determine whether or not the patient is an appropriate candidate for repair. Moreover, since considerable heterogeneity was permitted in the specific technique of repair-rigid (no specific conformation) or semi-rigid rings, with or without ventricular/papillary muscle/chordal maneuvers - there is no ability to distinguish whether or not the failure of repair was a result of patient selection or repair technique. As the data suggest, but far from prove, that those who have successful repair may actually have improved outcomes compared with those undergoing valve replacement, the ability to identify optimal candidates becomes a very important issue. Unfortunately, the answers to these questions, even after careful analysis of a carefully performed PRCT study, remain largely unanswered. As is so often the case, it is only through the careful integration of PRCT data with insightful analysis of retrospective trials that clinical relevance will emerge.

\section{References}

1. Agricola E, Oppizzi M, Pisani M, Meris A, Maisano F, Margonato A. Ischemic mitral regurgitation: mechanisms and echocardiographic classification. Eur J Echocardiogr. 2008;9:207-21.

2. Lamas GA, Mitchell GF, Flaker GC, Smith SC Jr, Gersh BJ, Basta L, et al Clinical significance of mitral regurgitation after acute myocardial infarction. Circulation. 1997;96:827-33.
3. Grigioni F, Enriquez-Sarano M, Zehr KJ, Bailey KR, Tajik AJ. Ischemic mitral regurgitation: long-term outcome and prognostic implications with quantitative Doppler assessment. Circulation. 2001;103:1759-64.

4. Di Salvo TG, Acker MA, Dec GW, Byrne JG. Mitral valve surgery in advanced heart failure. J Am Coll Cardiol. 2010;55:271-82.

5. Wu AH, Aaronson KD, Bolling SF, Pagani FD, Welch K, Koelling TM. Impact of mitral valve annuloplasty on mortality risk in patients with mitral regurgitation and left ventricular systolic dysfunction. J Am Coll Cardiol. 2005;45:381-7.

6. Mihaljevic T, Lam BK, Rajeswaran J, Takagaki M, Lauer MS, Gillinov AM, et al. Impact of mitral valve annuloplasty combined with revascularization in patients with functional ischemic mitral regurgitation. J Am Coll Cardiol. 2007; 49:2191-201.

7. Gasch WH, Meyer TE. Left ventricular response to mitral regurgitation: implications for management. Circulation. 2008;118:2298-303.

8. Beeri RY, Yosefy C, Guerrero JL, Nesta F, Abedat S, Chaput M, et al. Mitral regurgitation augments post-myocardial infarction remodeling failure of hypertrophic compensation. J Am Coll Cardiol. 2008;51:476-86.

9. Beeri R, Yosefy C, Guerrero JL, Abedat S, Handschumacher MD, Stroud RE, et al. Early repair of moderate ischemic mitral regurgitation reverses left ventricular remodeling: a functional and molecular study. Circulation. 2007;116(11 Suppl):1288-93.

10. Acker MA, Parides MK, Perrault LP, Moskowitz AJ, Gelijns AC, Voisine P, et al. Mitral-valve repair versus replacement for severe ischemic mitral regurgitation. N Engl J Med. 2014;370:23-32.

11. Perrault LP, Moskowitz AJ, Kron IL, Acker MA, Miller MA, Horvath KA, et al. Optimal surgical management of severe ischemic mitral regurgitation: to repair or to replace? J Thorac Cardiovasc Surg. 2012;143:1396-403.

12. Kron IL, Hung JW, Overvey JR, Bouchard D, Gelifins AC, Moskowitz AJ, et al. Predicting recurrent mitral regurgitation after mitral valve repair for severe ischemic mitral regurgitation. J Thorac Cardiovasc Surg. 2015;149:752-61.e1.

13. Hung J, Papakostas L, Tahta SA, Hardy BG, Bollen BA, Duran CM, et al. Mechanism of recurrent ischemic mitral regurgitation after annuloplasty: continued LV remodeling as a moving target. Circulation. 2004;110(Suppl 2): 1185-90.

14. McGee ED, Gillinov AM, Blackstone EH, Rajeswaran J, Cohen G, Najam F, et al. Recurrent mitral regurgitation after annuloplasty for functional ischemic mitral regurgitation. J Thorac Cardiovasc Surg. 2004;128:916-24.

15. Marwick TH. Restrictive annuloplasty for ischemic mitral regurgitation: too little or too much? J Am Coll Cardiol. 2008;51:1702-3. 